\author{
ЭКОСИСТЕМНЫЕ БЛАГА И ЭФФЕКТИВНОСТЬ ОХРАНЯЕМЫХ \\ ПРИРОДНЫХ ТЕРРИТОРИЙ В ГОРАХ: СРАВНИТЕЛЬНАЯ ОЦЕНКА МНЕНИЯ \\ НАСЕЛЕНИЯ БОЛГАРСКИХ РОДОП И РУССКОГО АЛТАЯ \\ Черных Д.В. ${ }^{1,2}$, Лубенец Л.Ф. ${ }^{1}$, Глушкова М. ${ }^{3}$, Жиянски М. ${ }^{3}$ \\ ${ }^{1}$ Институт водных и экологических проблем СО РАН, Барнаул, Россия \\ chernykhd@mail.ru, lilia_lubenets@mail.ru \\ ${ }^{2}$ Алтайский государственный университет, Барнаул, Россия \\ 3 Лесной институт Болгарской академии наук, София, Болгария \\ m_gluschkova@abv.bg,miglena.zhiyanski@gmail.com
}

\title{
ECOSYSTEM BENEFITS AND EFFICIENCY OF PROTECTED NATURAL TERRITORIES IN THE MOUNTAINS: A COMPARATIVE ASSESSMENT OF THE OPINION OF THE BULGARIAN RODOPES AND RUSSIAN ALTAI POPULATION Chernykh D.V. ${ }^{1,2}$, Lubenets L.F. ${ }^{1}$, Glushkova M. ${ }^{3}$, Zhiyanski M. ${ }^{3}$ \\ ${ }^{1}$ Institute of Water and Ecological Problems SB RAS, Barnaul, Russia \\ ${ }^{2}$ Altai State University, Barnaul, Russia \\ ${ }^{3}$ Forestry Institute of the Bulgarian Academy of Sciences, Sofia, Bulgaria
}

Сохранение всего объема экосистемных благ в горах связывается с охраняемыми природными территориями. В основу исследования положено интервьюирование населения в пределах модельных горных территорий Болгарии (Родопы) и России (Алтай) относительно представлений о благах, предоставляемых горными ландшафтами и эффективности охраняемых природных территорий. Всего было опрошено 374 человека. Приводятся результаты интервьюирования, иллюстрирующие как общие взгляды, так и различия во взглядах у населения модельных регионов.

Ключевые слова: экосистемные блага и услуги, охраняемые природные территории, Родопы, Русский Алтай, интервьюирование.

The preservation of total ecosystem benefits in the mountains is associated with protected natural areas. The study is based on the interviewing of population from the model mountain territories of Bulgaria (Rhodope) and Russia (Altai) about the benefits provided by mountain landscapes and the effectiveness of protected natural areas. A total of 374 people were interviewed. The interviewing results illustrate both common and different views of people from these model regions.

Keywords: ecosystem goods and services, protected areas, Rhodopes, Russian Altai, interview.

\section{Введение}

В настоящее время в рамках концепции экосистемных услуг (ЭУ) все большее внимание привлекают горные регионы. Ландшафты в горах являются важным элементом природного капитала и культурного наследия как внутри самих горных систем, так и за их пределами. В то же время, горная среда, в силу экстремальности природных условий, рассматривается как хрупкая и остро реагирующая на внешние воздействия природного и антропогенного генезиса.

Горные регионы Болгарии и России, как и повсюду в мире, привлекают большое количество туристов. Однако, значительные рекреационные потоки, с целью использования многочисленных ЭУ, предоставляемых горными ландшафтами, нередко являются негативным фактором с точки зрения защиты биоразнообразия. В этой связи сохранение всего объема экосистемных благ горных регионов связывается с охраняемыми природными территориями (ОПТ) - национальными и природными парками, заповедниками и их зонами сотрудничества.

В горах Болгарии и России сосредоточено значительное количество ОПТ, которые созданы для сохранения разнообразия видов и местообитаний, а также для защиты конкретных ландшафтов [2; 3 ; 4]. В то же время горные районы часто являются удаленными от основных экономических центров, а 
население в них очень уязвимо к экологическим, экономическим и социальным изменениям от местного до глобального масштаба. При этом население в горных районах более тесно связано с природой, в частности, сильно зависит от лесов, которые предоставляют им широкий спектр услуг, включая такие основные, как топливо, продукты питания, чистая вода и защита от стихийных бедствий. Такие особенности горных территорий, как большее, по сравнению с равнинами, количество девственных лесов, большее накопление углерода и большее биоразнообразие, обусловлены удаленностью и недоступностью, но делают местные сообщества социально, экономически и политически изолированными.

Всесторонняя оценка экосистемных благ горных территорий должна включать разнообразные методы, в том числе и социологические, позволяющие собирать разнообразную информацию от множества заинтересованных сторон [6]. Одной из наиболее эффективных форм оценок в данном случае является проведение содержательного интервьюирования с местным населением относительно его представлений о выгодах, исходящих от горных экосистем [1] на основе специальных опросников [5; 7].

В основу данного исследования положено интервьюирование населения в пределах модельных горных территорий Болгарии и России относительно его представлений о благах, предоставляемых горными ландшафтами. Для проведения оценки был составлен специальный опросник, который содержит вопросы, позволяющие оценить не только значимость и привлекательность ландшафтов территории, но и выявить готовность людей оберегать и сохранять блага природы. При этом основная цель исследования - на основе данных интервьюирования проанализировать и сравнить мнения населения Болгарских Родоп и Русского Алтая относительно объема природных благ, предоставляемых горными экосистемами, и эффективности охраняемых природных территорий в горах.

В рамках поставленной цели решались следующие задачи:

1) выявить наиболее значимые с точки зрения местного населения природные блага, предоставляемые экосистемами в Родопах (Болгария) и на Алтае (Россия);

2) выявить природные и культурные объекты в пределах модельных горных территорий, представляющие наибольший интерес для местных жителей и туристов;

3) определить эстетические предпочтения населения;

4) оценить с позиций местного населения роль ОПТ в сохранении потенциала экосистемных услуг;

5) проанализировать степень готовности местного населения платить за пользование природными благами на территории их проживания.

\section{Территория исследования}

В качестве модельных регионов определены Родопы в Болгарии и Алтай в России. Интервьюирование проводилось в Смолянской области (Болгария) и в Усть-Коксинском районе Республики Алтай (Россия).

Смолянская область находится на юге Болгарии и граничит с Грецией. В области имеется 25 охраняемых территорий, включая природные объекты Natura 2000, резерваты и так называемые «поддерживаемые резерваты» Сосковчето, Казаните и Кастракли, Момчиловски дол, Амзово, Шабаница.

Усть-Коксинский административный район расположен в юго-западной части Республики Алтай и граничит с Республикой Казахстан. В пределах района расположены Катунский биосферный заповедник, природный парк Белуха с самой высокой вершиной Сибири и несколько памятников природы.

\section{Исходные данные и методы исследования}

Интервьюирование населения, направленное на оценку экосистемных благ населением и выявление отношения местных жителей к ОПТ, выполнялось в феврале-октябре 2020 г.

Опросник, на основе которого проводилось исследование, включал 17 вопросов, объединенных в три блока. Блок 1 содержит вопросы, позволяющие получить информацию о том, какие блага местное население получает от окружающих ландшафтов. Вопросы блока 2 позволяют выявить эстетические предпочтения населения и его отношение к ОПТ. Вопросы блока 3 направленны на выявление готовности местного населения платить за те экосистемные блага, которыми оно пользуются. 
В исследовании приняли участие 374 человека, в том числе 227 из России и 47 из Болгарии. В России это жители девяти поселений зоны сотрудничества заповедника «Катунский» - сел УстьКокса, Катанда, Верх-Уймон, Мульта, Нижний Уймон, Тихонькая, Горбуново, Огневка, п. Октябрьское и жители 4 поселений, не входящих в зону сотрудничества заповедника - села Кастахта, Курунда, Чендек и п. Тюгурюк. В Болгарии были опрошены жители пяти поселений - г. Смолян, с. Борино, г. Девин, г. Доспат и г. Чепеларе.

\section{Результаты}

Наиболее значимые с точки зрения местного населения экосистемные блага. Среди наиболее востребованных благ, предоставляемых ландшафтами населению на территориях их проживания, чаще всего в обеих странах назывались: продукты питания растительного происхождения; благоприятные условия для развития животноводства (пастбища, сенокосные угодья) и питьевая вода (табл. 1). В Болгарии значительный процент опрошенных назвали деловую древесину, а в России - дрова.

Таблица 1

Наиболее ценные для местных жителей блага, предоставляемые ландшафтами

\begin{tabular}{|c|c|c|c|c|}
\hline \multirow[t]{2}{*}{ № } & \multirow{2}{*}{\multicolumn{2}{|c|}{ Природное благо }} & Болгария & Россия \\
\hline & & & \multicolumn{2}{|c|}{ доля ответивших, \% } \\
\hline 1 & \multirow{3}{*}{$\begin{array}{l}\text { Продукты питания растительного } \\
\text { происхождения }\end{array}$} & Ягоды & 99 & 63 \\
\hline 2 & & Грибы & 27 & 55 \\
\hline 3 & & травы (в т.ч. лекарственные травы) & 26 & 38 \\
\hline 4 & \multicolumn{2}{|c|}{ Благоприятные условия для развития животноводства } & 55 & 30 \\
\hline 5 & \multicolumn{2}{|c|}{ Питьевая вода } & 19 & 63 \\
\hline 6 & \multicolumn{2}{|l|}{ Деловая древесина } & 73 & 7 \\
\hline 7 & \multicolumn{2}{|l|}{ Дрова } & 21 & 52 \\
\hline 8 & \multicolumn{2}{|l|}{ Чистый воздух } & 18 & 11 \\
\hline
\end{tabular}

Из нематериальных благ, предоставляемых ландшафтами, возможность для отдыха назвали 82 \% опрошенных в Болгарии и $35 \%$ в России. Значительная доля опрошенных в Болгарии указали также на возможность развития туризма (64 \%) и наслаждения чистым воздухом (53\%); а в России - на возможность наслаждения неизмененными под действием человека ландшафтами (70 \%).

Природные и культурные объекты, представляющие наибольиий интерес для местных жителей и туристов. Наиболее популярные для посещения объекты (которые назвали более 30 \% респондентов) являются известными не только для модельных территорий, а также и для туристов из других стран: в Смолянской области - Devil's Bridge, Marvelous Bridges, Yagodinska Cave, Devil's Throat Cave; в Усть-Коксинском районе - гора Белуха и Мультинские озера (Google Search, Яндекс). Жители обеих стран называли также свои местные достопримечательности (менее 30 \%) (табл. 2).

Эстетические предпочтения местного населения. Респонденты, проживающие в Болгарских Родопах, отмечали, что, по их мнению, красивый пейзаж - это старовозрастные леса (76\%), озера (63 \%), горные вершины (52 \%) и зеленые луга (26 \%). Жителей Русского Алтая привлекают в первую очередь горные пейзажи (35\%). Кроме того, опрошенные часто указывали на то, что для них важно, чтобы горных рельеф сочетался с другими элементами (крутые склоны + лес + водоем) $(22 \%)$, и ландшафт был первозданным (19\%).

Подавляющее большинство опрошенных (в Болгарии $100 \%$, в России $92 \%$ ) на вопрос «Считаете ли Вы местность, которая окружает Вас, привлекательной в эстетическом отношении?» ответили утвердительно; в России $4 \%$ ответили, что не задумывались об этом и $4 \%$, что скорее да, чем нет.

На вопрос «Для Вас важно жить в окружении ландшафта с высокими эстетическими достоинствами?» в Болгарии $19 \%$ ответили, что очень важно, $81 \%$ - важно; в России - 76 \% и $17 \%$, соответственно. Также в России были ответы: не важно (5 \%) и абсолютно не важно (2 \%).

На вопрос «Как часто Вы посещаете места с красивыми пейзажами за пределами района вашего проживания?» в Болгарии $34 \%$ опрошенных ответили, что более 5 раз в год, $9 \%$ - что 3-4 раза в год, $27 \%,-$ что 1-2 раза в год и $29 \%$ - что реже одного раза в год; в России - 14\%, $11 \%$, 30 \%, 45 \%, соответственно.

Отношение местного населения к организации охраняемых природных территорий в местах их проживания. На вопрос «Как Вы оцениваете роль охраняемых территорий (заповедников, нацио- 
нальных парков и др.) в сохранении эстетической привлекательности ландшафтов?» в Болгарии $18 \%$ ответили, что эта роль, однозначно, положительная, $53 \%$ - эта роль скорее положительная, чем отрицательная, $29 \%$ - эта роль скорее отрицательная, чем положительная. В России ответов «однозначно положительная» было почти в три раза больше - 58 \%, а «скорее положительная, чем отрицательная» меньше - $34 \%$. Значительно меньше отмечали отрицательную роль $-7 \%$, и $1 \%$ указывали на то, что эта роль, однозначно, отрицательная; $1 \%$ - затруднились ответить.

Таблица 2

Природные и культурные объекты территории исследования, представляющие наибольший интерес для посетителей (доля от общего количества ответивших*)

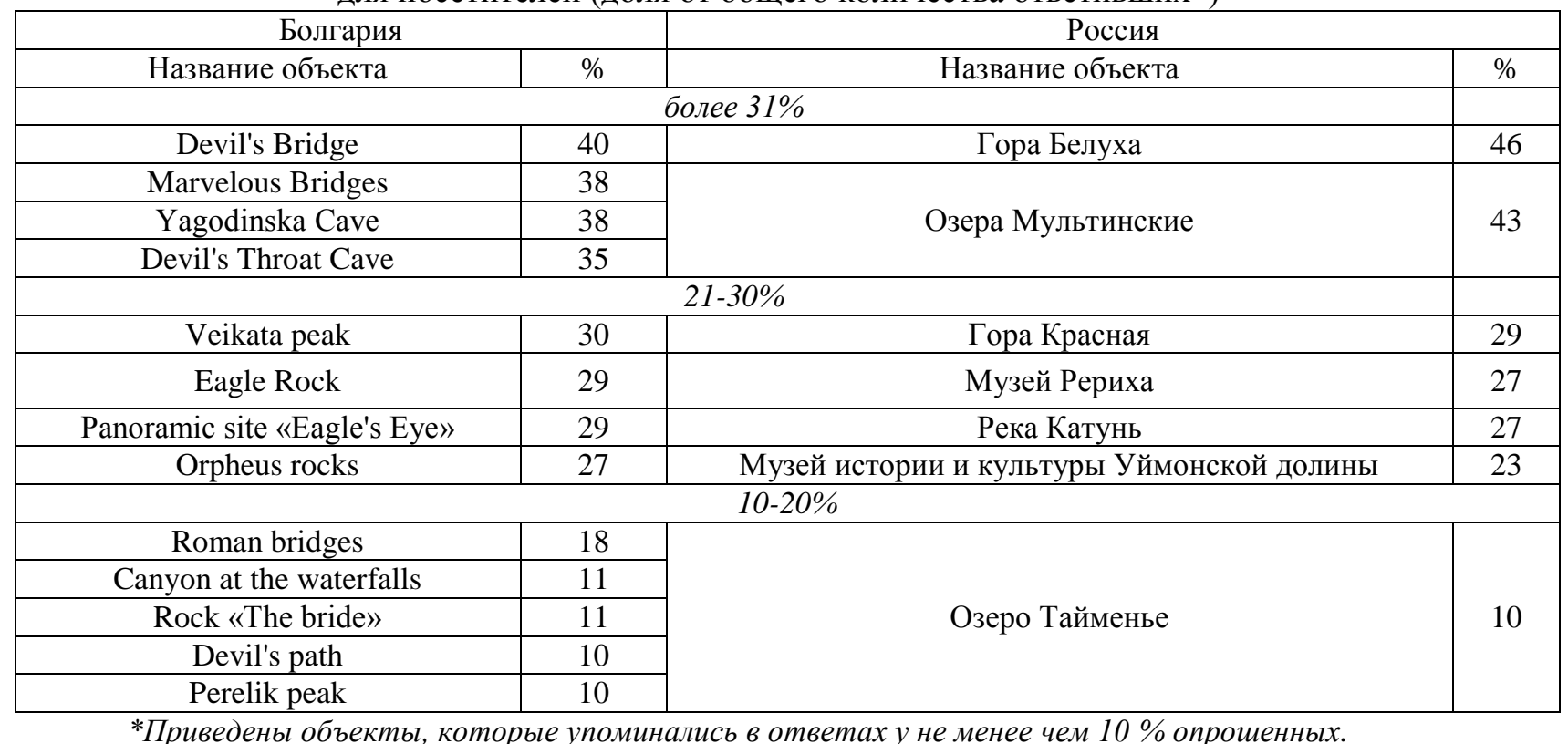

На вопрос «Приносит ли пользу местному населению наличие охраняемых природных территорий?» в Смолянской области Болгарии 43 \% ответили, что приносит однозначно, $13 \%$ - скорее да, чем нет, не было ответов - скорее нет, 44 \% ответили, что не приносит; в Усть-Коксинском районе $52 \%, 33 \%, 11 \%, 4 \%$, соответственно.

Готовность жителей платить за пользование природными благами на территории их проживания. В Болгарии на вопрос «Согласны ли Вы на введение рекреационного налога на Вашей территории?» отрицательно ответили $64 \%$, положительно - $36 \%$; в России - $52 \%$ и $48 \%$, соответственно. При этом то, что отдыхающие должны платить за возможность наслаждаться красивым пейзажем в Болгарии считают 88 \% опрошенных; в России - лишь $43 \%$. Оказать разовую материальную поддержку для улучшения экологического состояния местности в районе проживания в Болгарии готовы $90 \%$ опрошенных, оказывать такую поддержку на регулярной основе готовы $91 \%$; в России - $24 \%$ и $68 \%$, соответственно.

\section{Заключение и выводы}

Интервьюирование является одним из наиболее эффективных методов оценки предпочтений относительно благ, предоставляемых населению экосистемами, и оценки эффективности охраняемых природных территорий.

Результаты проведенного в период с февраля по октябрь 2020 г. на двух модельных горных территориях Болгарии и России интервьюирования показали следующее.

1. Жители Смолянской области (Болгария) и Усть-Коксинского района (Россия) рассматривают в качестве важнейших экосистемных благ в горах продукты питания растительного происхождения, благоприятные условия для развития животноводства (пастбища, сенокосные угодья) и питьевую воду.

2. Среди нематериальных благ, предоставляемых людям горными ландшафтами, население обеих стран отмечает возможность отдыха и развития туризма, а также чистый воздух (Болгария) и наслаждение естественными ландшафтами (Россия). 
3. В перечне природных и культурных объектов, расположенных в пределах модельных территорий и представляющих наибольший интерес для посетителей, респонденты на первое место поставили объекты, известные за пределами изучаемых стран: в Болгарии - Devil's Bridge, Marvelous Bridges, Yagodinska Cave, Devil's Throat Cave; в России - гора Белуха и Мультинские озера.

4. Большинство жителей обеих стран, принимавших участие в опросах, оценивают территорию своего проживания как эстетически привлекательную.

5. Жители России более однозначно оценивают положительную роль охраняемых природных территорий $(58$ \%). В Болгарии более половины опрошенных (53 \%) считают, что это роль скорее положительная, чем отрицательная.

6. Большая часть опрошенных в Смолянской области Болгарии ( 88 \%) считает, что отдыхающие должны платить за возможность наслаждаться красивым пейзажем, однако более половины (64 \%) против введения рекреационного налога. В Усть-Коксинском районе России такого мнения придерживаются менее половины жителей - 43 \% и 48 \%, соответственно.

Исследование выполнено при финансовой поддержке РФФИ, проект № 19-55-18001_Болг_а.

\section{Список литературы}

1. Bieling C., Plieninger T. Recording manifestations of cultural ecosystem services in the landscape. Landscape Research. 2013, 38(5), pp. 649-667.

2. Brooks T., Da Fonseca G.A.B., Rodrigues A. S.L. Species, Data, and Conservation Planning. Conservation Biology. 2004, 18(6):1682-1688.

3. Butchart S. H. M. et al. Global Biodiversity: Indicators of Recent Declines. Science. 2010, 328:1164-1168.

4. Coad L., Burgess N.D., Fish L., Ravillious C., Corrigan C., Pavese H., Granziera A., Besançon C. Progress towards the convention on biological diversity terrestrial 2010 and marine 2012 targets for protected area coverage. Parks. 2008, 17, pp. 35-42

5. Grêt-Regamey A., Bishop I.D., Bepi P. () Predicting the scenic beauty value of mapped landscape changes in a mountainous region through the use of GIS. Environment and Planning B. 2007, 34, pp. 50-67.

6. Palomo, I., Montes, C., Martín-Lopez, B., Gonzalez, J. A., García-Llorente, M., Alcorlo, P., et al. Incorporating the socialeecological approach in protected areas in the Anthropocene. Bioscience. 2014, 64, pp. 181-191.

7. Schirpke, U., Tasser, E., Tappeiner, U. Mapping ecosystem services supply in mountain regions: a case study from South Tyrol (Italy). Annals of Botany, 2014, 4, pp. 35-43. 